DR. EMMA KNOWLES (Orcid ID : 0000-0003-0642-267X)

3

4

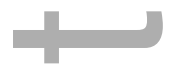

5 Received Date :06-Oct-2016

6 Revised Date : 03-Jan-2017

7 Accepted Date: 10-Jan-2017

8 Article type : Original Article

9

\title{
Serum Phosphatidylinositol as a Biomarker for Bipolar Disorder Liability
}

Emma. E. M. Knowles $\mathrm{PhD}^{1^{*}}$, Peter J Meikle $\mathrm{PhD}^{2}$, Kevin Huynh $\mathrm{BSc}^{2}$, Harald, H. H. Goring PhD ${ }^{3}$,

Rene L. Olvera $\mathrm{MD}^{4}$, Samuel R. Mathias ${ }^{1}$, Ravi Duggirala $\mathrm{PhD}^{3}$, Laura Almasy $\mathrm{PhD}^{5}$, John Blangero

${ }^{1}$ Department of Psychiatry, Yale University School of Medicine, New Haven, CT, USA

${ }^{2}$ Baker IDI Heart and Diabetes Institute, Melbourne, Australia.

${ }^{3}$ South Texas Diabetes and Obesity Institute, University of Texas of the Rio Grande Valley School of Medicine, Brownsville, TX, USA

${ }^{4}$ Department of Psychiatry, University of Texas Health Science Center at San Antonio, San

(1)

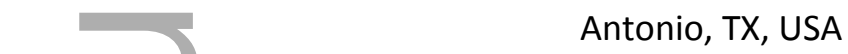

${ }^{5}$ Department of Genetics at University of Pennsylvania and Department of Biomedical and

Health Informatics at Children's Hospital of Philadelphia, PA, USA

${ }^{6}$ Olin Neuropsychiatric Research Center, Institute of Living, Hartford Hospital, Hartford, CT, USA

This is the author manuscript accepted for publication and has undergone full peer review but has not been through the copyediting, typesetting, pagination and proofreading process, which may lead to differences between this version and the Version of Record. Please cite this article as doi: $10.1111 /$ bdi.12468

This article is protected by copyright. All rights reserved 
*Correspondence to: Emma. E. M. Knowles, Department of Psychiatry, Yale University, 40

Temple Street, Office 6C, New Haven, 06511, CT, USA. E-mail: emma.knowles@yale.edu.

.

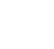

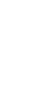

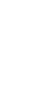

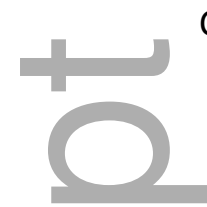

Conflict of Interest: The authors declare no conflict of interest.

Running head: Phosphatidylinositol as a Bipolar Biomarker

-
Keywords: Bipolar; Lipidome; Phosphatidylinositol; Genetics; Family Study

\begin{abstract}
\end{abstract}
Objectives Individuals with bipolar disorder (BPD) exhibit alterations in their phospholipid levels.

It is unclear whether these alterations are a secondary consequence of illness state, or if phospholipids and illness risk overlap genetically. If the latter were true, then phospholipids might provide key insights into the pathophysiology of the illness. Therefore we rank-ordered phospholipid classes by their genetic overlap with BPD risk in order to establish which class might be most informative in terms of increasing our understanding of illness pathophysiology.

Methods Analyses were conducted in a sample of 558 individuals, unselected for BPD, from extended 38 extended pedigrees (average family size $=14.79$, range $=2-82$ ). We calculated a coefficient of relatedness for all family members of 9 individuals with BPD in the sample $(\mathrm{N}=185)$, this coefficient was set to be zero in unrelated individuals $(\mathrm{N}=373)$. Then under an endophenotype ranking value (ERV) approach this scalar index was tested against thirteen serum-based phospholipid concentrations in order to rank order lipid classes by their respective overlap with BPD risk.

Results The phosphatidylinositol class was significantly heritable $\left(h^{2}=0.26, p=6.71 \times 10^{-05}\right)$. It was the top-ranked class, and was significantly associated with BPD risk after correction for multiple testing $\left(\beta=-1.18, p=2.10 \times 10^{-03}, E R V=0.49\right)$.

Conclusions We identified a peripheral biomarker, serum-based phosphatidylinositol, which exhibits a significant association with BPD risk. Therefore, given that phosphatidylinositol and BPD risk share partially common etiology, it seems that this lipid class warrants further investigation, not only in terms of treatment, but also as a promising diagnostic and risk marker.

\title{
Introduction
}

This article is protected by copyright. All rights reserved 
Identifying endophenotypes for bipolar disorder will garner greater understanding of psychiatric

2 illnesses, including bipolar disorder, which in turn will aid in their identification, diagnosis and

3 treatment (1-3). An endophenotype is a biomarker, or measurable characteristic, that is

4 associated with disease (4). Crucially, an endophenotype must share some appreciable portion

5 of its genetic etiology with disease risk (4). This requirement is important because it implies that

6 some portion of the biological processes that underlie the endophenotype overlap with those

7 that are disrupted in disease. Thus, the identification of endophenotypes for psychiatric illnesses

8 should contribute to our understanding of illness pathophysiology (5). Peripheral markers, such

9 as serum-based lipid measurements, hold great promise as endophenotypes for two reasons.

10 First, their underlying biochemical underpinnings are relatively well understood, particularly

11 when compared to, for example, brain- or behavior-based phenotypes. Second, peripheral

12 markers are easily obtainable at comparatively low cost (6). These advantages are particularly

13 appealing for bipolar disorder (BPD), a psychiatric illness that is ranked as one of the leading

14 causes of disability and premature mortality worldwide (7-9), but whose physiological

15 underpinnings are still largely unknown (10).

17 Lipids and their polyunsaturated fatty acids (PUFAs) constitute basic and essential components

18 of all human cells, both in terms of structure, making up the major component of cell

19 membranes, and function, where they play a part in neurotransmission, receptor function, and

20 eicosanoid biosynthesis $(11,12)$. A number of lipidomic alterations been noted in those with BPD

21 and also major depressive disorder (MDD) (13). For example, increases in plasma-levels of lipid

22 peroxidation have been noted in euthymic adults with BPD (6) while decreases are noted in

23 adolescent BPD individuals (14). It has been shown that essential polyunsaturated fatty acids in

24 red blood cell membranes, including arachadonic and docosahexaenoic acid (DHA), are reduced

25 BPD individuals in a manic phase (15) and in those with MDD (16); and that the fatty acid

26 composition of phospholipids in serum is altered in those with MDD such that the

27 arachadonic/eicosapentaenoic acid ratios are higher $(17,18)$. Accordingly, a handful of studies

28 suggest that administration of fatty acids may have benefits in the amelioration of mood

29 symptoms (19-21). Brain-based findings, both in vivo and in vitro, indicate significant elevations

30 of phosphatidylcholines in the prefontal cortex (22), significantly reduced choline in the frontal

31 lobe (23), and reduced DHA in the orbitofrontal cortex (24) in BPD individuals. In sum, there is

32 evidence for alterations in phospholipids and their fatty acids in BPD and MDD, the direction of

This article is protected by copyright. All rights reserved 
1 those alterations is currently unclear, probably in part because of heterogeneity in methods and patient populations. Though a recent and large study on this topic, which utilized plasma-based

3 lipid levels, documented an inverse relationship between phospholipid levels and symptoms of

4 depression (26). The present study is the first to examine the influence of genetic liability for

$5 \quad$ BPD on serum-based phospholipids.

Phosphatidylinositol (PI) (a membrane phospholipid that plays a crucial role in cell physiology and signaling (27)) and its phosphorylated products phosphoinositides (PtdIns) are particularly interesting in the context of BPD, given that lithium $\left(\mathrm{Li}^{+}\right)$, the first-line mood stabilizer treatment for BPD (28), acts upon the PI signal transduction pathway (29). While there is converging evidence for inositol phospholipid system dysfunction in BPD (30-38), more work is necessary in order to clarify the relationship between them (39). Of course, given the link between phospholipids and the mechanism of action of $\mathrm{Li}^{+}$, it is possible that alterations in lipid levels arise as a secondary consequence of treatment for BPD. This is why establishing such a peripheral marker as an endophenotype of BPD is particularly important, as alterations are demonstrated as a function of genetic proximity to an affected individual, that is in unaffected relatives who are not exposed to bipolar treatment regimens (5). The implication being that alterations in serum phospholipid levels arise as a consequence of shared genetic etiology making them and their underlying biochemical mechanisms potentially promising diagnostic

In the present study we aimed to (1) provide evidence for shared genetic etiology between phospholipid concentrations and BPD risk, and (2) determine which phospholipid classes might be the most informative when attempting to isolate potential diagnostic and treatment targets for BP. We took sum concentrations of thirteen phospholipid classes in a sample of 558 Mexican American individuals from 38 randomly ascertained extended pedigrees, and calculated meanbased Endophenotype Ranking Values (40) between each phospholipid class and a broad BPD phenotype (incorporating BPD Type I and II). We used this broad BPD phenotype to increase the total number of included affected individuals, which in turn reduces the noise associated with

31 any single diagnosis and maximizes power.

This article is protected by copyright. All rights reserved 
2 Lipidomic and diagnostic data were available in 567 individuals from 38 pedigrees (average

3 family size $=14.79$, range $=2-82$ ). The sample was $64 \%$ female and had a mean age of 49.28

4 years $(S D=13.34$, range $=27-97)$. The lipidomic data was collected as part of the San Antonio

5 Family Study (SAFS), diagnostic data were also available in these same individuals as part of

6 assessments conducted in the Genetics of Brain Structure and Function (GOBS) study. GOBS

7 data collection occurred between 2006 and 2016. Of the 567, 9 persons had received a BPD

8 diagnosis (BPD Type I $(N=4)$ and II $(N=5)$; see Table 1 for additional diagnostic information).

9 Affected individuals were excluded from the analysis and therefore analysis was run in 558

10 individuals, this comprised 185 individuals related to an affected plus 373 unrelateds (Table 2).

12 All participants were randomly selected from the community with the constraints that they were of Mexican American ancestry, part of a large family, and lived in the San Antonio region. All participants provided written informed consent in compliance with the institutional review board at the University of Texas Science Center of San Antonio.

Diagnostic Assessment

The Mini-International Neuropsychiatric Interview (MINI; (41)), a semi-structured interview, was administered to all participants. Interviews were conducted by masters- and doctorate-level research staff, who had established reliability for diagnosing bipolar disorder ( $k \geq 0.85$ ). Subjects that reported possible pathology were discussed in case conference meetings with licensed psychologists and/or psychiatrists. Consensus diagnoses were determined using available medical records, the MINI, and the interviewer's narrative.

Lipid Extraction and Analysis Procedure

26 The lipid extraction procedure used in this sample has been described in detail elsewhere (see

$27(42,43)$. Briefly, lipid extraction in the San Antonio Family study is part of an ongoing longitudinal 28 observational investigation comprising four phases of data collection during a 23-year period.

29 The lipidomic data used in the present study were collected during the first phase, between the years 1992-1996. The order of the plasma samples was randomized prior to lipid extraction and

31 analysis for each cohort. Quality control plasma samples were included at a ratio of 1:18. Total 
1 lipid extraction from a $10 \mathrm{~mL}$ aliquot of plasma was performed by a single phase

2 chloroform:methanol (2:1) extraction (44).

3

$4 \quad$ Lipid analysis was performed by liquid chromatography, electrospray ionisation-tandem mass 5 spectrometry using a Agilent 1200 liquid chromatography system combined with an Applied 6 Biosystems API 4000 Q/TRAP mass spectrometer with a turboionspray source (350uC) and 7 Analyst 1.5 data system (44). We have previously reported the use of precursor ion and neutral 8 loss scans on control plasma extracts to identify the predominant lipid species of the following 9 phospholipid classes: sphingomyelin (SM), phosphatidylcholine (PC), alkylphosphatidylcholine $10(P C(O))$, alkenylphosphatidylcholine (plasmalogen, $P C(P))$, lysophosphatidylcholine (LPC), 11 lysoalkylphosphatidylcholine (lysoplatelet activating factor, LPC(O)), phosphatidylethanolamine 12 (PE), phosphatidylinositol (PI), phosphatidylserine (PS), and phosphatidylglycerol (PG) (44-46). Multiple Reaction Monitoring (MRM) experiments were established for the major species of each lipid class identified in plasma. Relative lipid amounts were calculated by relating the peak area of each species to the peak area of the corresponding stable isotope or non-physiological

17 internal standard. Total lipid classes were calculated from the sum of the individual lipid species 18 within each class (43).

Quantitative Genetic Analysis

21 All genetic analyses were performed in SOLAR (47). SOLAR implements a maximum likelihood 22 variance decomposition to determine the proportion of variation in a phenotype due to genetic 23 and environmental influences by modeling the covariance amongst family members as a 24 function of genetic proximity. The simplest such decomposition is one where the additive 25 genetic contribution of a trait is indexed by the heritability, or $h^{2}$. All lipid classes were subject to 26 univariate decomposition analysis to ensure that they were significantly heritable.

Genetic Correlation between BPD and Lipid Classes: The Mean-Based Endophenotype Ranking Value (mERV)

The mean-based endophenotype ranking value (mERV) represents an extension of the endophenotype ranking value $(E R V)$. The $E R V$, an effect size ranging between 0 and 1 , was 
1 developed for the purpose of formally testing endophenotypic status of phenotypes and to rank

2 phenotypes by their standardized genetic covariance with a disease of interest; it is expressed as 3 follows:

4

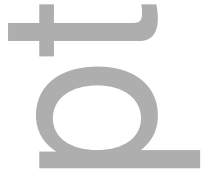

$$
E R V=\sqrt{h_{D}^{2} h_{E}^{2}}\left|\rho_{G}\right|
$$

6 Where $h_{D}^{2}$ is the heritability of disease risk, $h_{E}^{2}$ is the heritability of the endophenotype, and $\rho_{G}$

7 is the genetic correlation between the two (48). The $m E R V$ is an extension of the $E R V$ to be used

8 when the disease of interest is not sufficiently common in the data. For details on the derivation

9 of the mERV, see Glahn et al (2015) (40). Briefly, the mERV leverages the many coefficients of relationship that exist in extended-pedigree data. The coefficient of relationship refers to the

11 average number of alleles held in common between individuals; for example, first-degree

12 relatives (e.g. full siblings or parents) share on average $50 \%$ of their alleles, second-degree

13 relatives (e.g. grandparents or aunts/uncles) share $25 \%$, third-degree relatives (e.g. great 14 grandparents or great-aunts/-uncles) share $12.5 \%$, and so on. Thus it is possible, given an 15 individual with a disease, to index all other pedigree members by their degree of relatedness to 16 that individual. This scalar can then be used to perform a fixed-effect single-degree-of-freedom 17 test, within the univariate variance components analysis outlined above, providing an estimate 18 of the standardized genetic covariance between the potential endophenotype and illness risk. 19 The mERV can then be used in the same way as the ERV to rank potential endophenotypes by 20 their degree of standardized genetic overlap with illness risk. In the present manuscript the $21 \quad m E R V$ was applied to BPD and all available lipid classes.

We Bonferroni-corrected $\alpha(=0.05)$ by the effective number of traits using the method outlined by Cheverud (49), correcting for the total number of traits would be overly conservative, given the extent to which they are all correlated with one and other (50). Applying this method to the pairwise genetic correlations between the 13 phospholipid classes reveals that we have 10.36 effective traits, thus $\alpha=0.05 / 10.36=4.82 \times 10^{-03}$.

We tested the potential influence of confounding variables, in particular BMI and Major Depressive Disorder (MDD), on all lipid classes. We tested the potential genetic overlap, using a 
bivariate polygenic model, between the lipids and potential psychiatric and metabolic

2 confounds. We then included those covariates with a significant genetic overlap with the lipid 3 class, using liberal threshold of $p<0.10$ in order to increase confidence that important

4 covariates were included, in the univariate polygenic model described above in addition to the BPD coefficient of relationship (which was fixed in the model). We tested the following variables

6 that were collected at the time of blood sampling as part of the SAFS assessment (51): BMI; diabetes status; ever had a heart attack; smoking status; and hypertension status. In addition we investigated the following variables from the GOBS assessment taken from the MINI (41): any depressive disorder; any anxiety disorder; any alcohol use disorder; any substance use disorder.

\section{Results}

Family profiles

13 According to our consensus diagnoses nine individuals met the criteria of our broad BPD 14 phenotype, 4 individuals met criteria for BPD I and 5 met criteria for BPD II. Table 2 shows the

Indexing Genetic Relatedness Between BPD Liability and All Lipid Classes

20 The heritability of all lipid classes are shown in Table $\mathbf{3}$ inspection of which indicates each class is

21 significantly heritable. Also shown in Table 3 are the $\beta$ estimates from the $m E R V$ analysis along 22 with the p-values of which one withstood a multiple testing correction, the PI 23 (phosphatidylinositol) class $\left(\beta=-1.18, \mathrm{p}=2.10 \times 10^{-03}, E R V=0.49\right)$, this class was deemed to be 24 significantly heritable $\left(h^{2}=0.26\right.$, se $\left.=0.08, p=6.71 \times 10^{-05}\right)$.

Investigating The Influence of Potential Confounds: Metabolic and Psychiatric

27 Of the metabolic variables only Diabetes Status $\left(\rho_{q}=0.35\right.$, se $\left.=0.15, p=0.03\right)$ was significantly 28 associated with PI levels. None of the other metabolic covariates (including BMI, Hypertension, 29 Heart Attack, or Smoking Status) were significantly associated with PI. Of the psychiatric diagnoses only alcohol use disorders was significantly associated with PI levels $\rho_{q}=-0.58$, se $=$

$310.28, p=0.04)$. None of the other psychiatric diagnoses (including depression, anxiety or 
1 substance abuse) were significantly associated with PI. Thus, aside from diabetes status and

2 alcohol use disorders, given the lack of significant genetic overlap between the other metabolic

3 and psychiatric phenotypes we assumed that we need not covary for them when investigating

4 the genetic overlap between BPD risk and PI. Most notably, neither BMI nor major depression

5 demonstrate a shared etiology with serum levels of PI in the present sample, and accordingly

6 neither are likely to be confounding factors in the association between BPD risk and PI that is

7 present in the sample.

9 After controlling for diabetes status (in addition to age, age ${ }^{2}$, sex, plus their interactions) first

10 degree relatives of affected individuals exhibited lower levels of phosphatidylinositol than 11 unaffected, unrelated controls (Cohen's $d=-0.53$ ), while $2-7^{\text {th }}$ degree relatives exhibited levels 12 intermediary between $1^{\text {st }}$ degree relatives (Cohen's $d=0.46$ ) and controls (Cohen's $d=-0.52$ ).

13 The levels of PI in cases, unaffected relatives and unaffected unrelateds are shown in Figure 1. In

14 general it appears the PI levels vary as a function of genetic proximity to an affected individual.

15 It is important to note that cases were not included in the analyses outlined above, and thus 16 their seemingly anomalous PI levels should not be of concern, firstly there are only 9 cases and 17 secondly their PI levels are subject to confounding factors such as, for example, mood stabilizing medication

\section{Discussion}

21 In the present study we investigated the relative genetic overlap between bipolar disorder (BPD)

22 risk and thirteen phospholipid classes, this was in an effort to rank the phospholipids according

23 to which might be most informative when attempting to disentangle the etiology of BPD. To our

24 knowledge, this is the first study to investigate possible genetic overlap between BPD risk and

25 serum phospholipid levels. The existence of significant genetic overlap between BPD risk and

26 phospholipid levels, and more specifically between illness risk and phosphatidylinositol, strongly

27 suggests that phosphatidylinositol is not merely a secondary manifestation of either illness state or treatment but rather an endophenotypic marker of the illness with the potential for aiding early detection and diagnosis, as well as enhanced treatment regimens.

31 Phosphatidylinositols are membrane phospholipids found mostly on the inner leaflet of the cell

32 and are characterised by an inositol ring, or head group, extending into the cytoplasm (52). 
1 Despite their relatively low abundance compared to other membrane lipids it is the metabolism

2 of this phospholipid class which gives rise to second messengers that are major contributors to

3 the myriad aspects of cellular regulation which make up the phosphatidylinositol signal

4 transduction pathway $(53,54)$. Phosphatidylinositol is implicated in well-characterized signal

5 transduction pathways, alterations in the molecular components of which, in particular $\mathrm{PIP}_{2}$ and

$6 \quad$ PKC levels, have been previously associated with BPD (55-67). The present study, to our

7 knowledge, is the first to suggest a shared etiology between serum phosphatidylinositol levels

8 and risk for BPD. Phosphatidylinositol is a particularly interesting candidate endophenotype for

9 BPD given that lithium ( $\mathrm{Li}+$ ), a mood stabilizing drug and treatment of choice for BPD (68), is

10 thought to act upon the phosphatidylinositol signaling pathway. The inositol-depletion

11 hypothesis posits that lithium acts by preventing the production of phosphatidylinositol via

12 inhibition of IMPase thereby limiting turnover of inositol in the cell $(29,68)$.

13 The direction of the relationship between BPD risk and phosphatidylinositol in the present study

14 was negative, meaning that heightened risk for BPD was associated with low levels of the

15 phospholipid. This is the only study, to our knowledge, to assess phospholipid levels in serum in

16 relation to BPD risk. However, Demirkan and colleagues also showed a negative correlation

17 between plasma-based phospholipids (phosphatidylcholine and sphingomyelin) and symptoms

18 and depression and anxiety (26). Therefore while our results are seemingly in keeping with the previous literature they are not necessarily what the inositol-depletion hypothesis might

20 predict, where Li+ theoretically works to decrease high levels of inositol in BPD subjects. Of

21 course the present study, like that of Demirkan and colleagues (26), relies on peripheral indices

22 of lipid levels. This allows us only to speculate on the ways in which these findings might be

23 interpreted in the brain. There is surprisingly little information in the literature regarding either

24 the direct origin of phosphatidylinositol in circulation or the relationship between levels in the

25 periphery and in the brain. Serum phosphatidylinositol is likely hepatic in origin as majority of

26 circulating lipids in lipoproteins are generated from the liver. The level of Pl's is dependent on

27 the availability of myo-inositol, which in turn is synthesized from glucose. The enzyme

28 responsible for all these steps are found in liver cells as well as other organs. There is evidence

29 to suggest that lipids, and their fatty acids are shuttled to the brain from the liver where they

30 play crucial roles in neuro-development, -inflammation and -protection (69-71).

This article is protected by copyright. All rights reserved 
1 Future work might attempt to pin down the levels of phospholipids in brain and even the

2 relationship between those levels in brain and the periphery. One such line of research might

3 utilize phosphorous-31 magnetic resonance spectroscopic (31P MRS), an imaging method that

4 allows non-invasive measurement of biological compounds (e.g. phospholipids) in vivo. In BPD

5 this technique has been used to demonstrate significantly reduced choline, indicating altered

6 phospholipid metabolism, in the frontal lobe (23). The PME (phosphomonesters) signal is 31P

$7 \quad$ MRS reflects the level of phosphocholine and phosphoethanolamine in addition to choline and

8 myo-inositol (72), there is evidence to suggest that the PME signal increase during manic states

9 and decrease during depressed states (73-76). Thus in addition to the unknown relationship

10 between phospholipid levels in the periphery and brain it is possible that a second level of

11 complexity exists where levels in both are affected by BPD illness phase. Evidence from post-

12 mortem studies for phospholipid alterations in brain in BPD is mixed where some have not

13 observed alterations in phospholipids and/or their fatty acids in BPD subjects versus controls

14 (77-79) while others have $(24,80)$. There is little consistency in terms of the focal brain region

15 across these studies, which may explain the inconsistencies in the results. In addition, it is

16 possible that lipidomic abnormalities in relation to affective disorders may be characterized

17 differently in other ethnic populations. For example, non-Hispanic populations exhibit altered

18 lipidomic profiles and associated risk for myocardial infarcation relative to Hispanics (81). Thus

19 overall, it is important that the generalizability of the findings in the present manuscript should

20 be further tested in future research.

21 In the present manuscript there was a gap in time between the collection of the lipidomic data

22 and the occurrence of the psychiatric assessments. There is relatively little known about the

23 longitudinal variability of serum phospholipid levels. There is evidence to suggest that

24 phospholipids vary as a function of age (82), and as a consequence we residualized the

25 phospholipid traits for age (in fact for age, age^^2, sex, plus their interactions) at the time of data

26 collection. We consider this a potential strength of the manuscript as it suggests that variation in

27 phosphatidylinositol reflects an early etiological step in the development of BPD. We cannot

28 investigate this in detail in the present sample, with the limited number of affected cases

29 available, but it is possible that the present results hint at alterations in phosphatidylinositol

30 reflect an "at-risk" condition for BPD. Certainly longitudinal studies of other peripheral markers,

31 in this case markers of inflammation, support an aetiological role of inflammation in risk for

32 major depressive disorder (83-85).

This article is protected by copyright. All rights reserved 
1 Two potential criticisms might be leveraged at the present study regarding the affected

2 individuals. The first criticism is that no two affected individuals with BPD occur in the same

3 family, thus negating the idea that genetic factors underlie the illness. However, the heritability

4 of BPD is not in question, having been established by numerous family based studies and large

5 GWAs previously (86). Also, it is not improbable that no two affected individuals would be part

6 of the same family. Rather what we would expect is that an individual with an affected relative

7 would have an increased risk for developing BPD compared to an individual without an affected

8 relative. This risk may not necessarily be represented phenotypically as the full manifestation of

9 the disorder within the relative's lifetime (or indeed by the time of assessment), but may

10 influence the expression of phenotypes related to the disorder. The second criticism is that only

11 nine affected individuals are included in the present study, but importantly these individuals

12 originate from extended pedigrees. Therefore because the question under investigation in this

13 study was one of genetic liability this sample, comprising multiple extended pedigrees

14 encapsulating many degrees of relatedness, provides the statistical power needed to adequately

15 test hypotheses about putative pleiotropy between phospholipids BPD risk. Indeed, an

16 advantage of large, extended pedigrees such as this (where family sizes varied between 2 and 82

17 individuals) is that many unaffected relatives, encapsulating many degrees of relatedness, are

18 available for a small number of cases (40). That being said, in subsequent work where we

19 attempt to finesse our hypotheses regarding phosphatidylinositol and its role in BPD we may

20 need greater numbers of probands.

21 The ERV is the product of three terms: the square root of the heritability of the endophenotype,

22 the square root of the heritability of the disease, and the absolute value of the genetic

23 correlation between the two. Similarly, the power of the ERV is a function of all three of these

24 components in the same way that the power of a genetic correlation is. While the heritability of

25 the endophenotypes (i.e. the phospholipid class) can be directly estimated in the present

26 sample, the heritability of BPD cannot, given that we have nine affecteds. For a single

27 endophenotype, the heritability of BPD is not identifiable (in the statistical sense) with this

28 method. However, in principle with enough endophenotypes, the heritability of BPD may be

29 estimable from the method due to the constraints on the parameter spaces of both the

30 heritability and the genetic correlation, but it would generally be difficult to resolve. The total

31 ERV, which our inference of genetic correlation/pleiotropy is based upon, is well estimated in

32 the design. One of the substantial benefits of this method of calculating the ERV is that it does

This article is protected by copyright. All rights reserved 
1 not require affected relatives of cases and thus is very useful for studying genetic determinants

2 (shared via endophenotypes) of low frequency diseases.

3 In summary, the findings presented here highlight phosphatidylinositol as having a significant

4 genetic overlap with BPD risk. While it has been previously demonstrated that those with BPD

5 exhibit altered levels of phospholipids this is the first study to highlight a shared genetic etiology

6 between the two. It is unlikely that the association between phosphatidylinositol and BPD risk in

7 the present study arose as an artifact of lithium treatment, as affected individuals were

8 excluded from all genetic analyses. Rather, the serum level of this lipid appears to vary in

9 unaffecteds as a function of genetic relatedness to a BPD individual and therefore the present

10 study highlights the potential utility of serum-level measurements of phosphatidylinositol as an

11 indicator of illness risk. Moreover, this study suggests that the well-characterized

12 phosphatidylinositol signaling pathway may be an interesting avenue of research for BPD,

13 potentially providing testable hypotheses for research aiming to improve diagnostic markers

14 and/or treatment targets for BPD.

References

16 1. Barnett JH, Smoller JW. The genetics of bipolar disorder. Neuroscience 2009; 164: 331-343.

17 2. Frey $B N$, Andreazza AC, Houenou J, Jamain S, Goldstein BI, Frye MA, Leboyer M, Berk M, Malhi

18 GS, Lopez-Jaramillo C, Taylor VH, Dodd S, Frangou S, Hall GB, Fernandes BS, Kauer-Sant'Anna M,

19 Yatham LN, Kapczinski F, Young LT. Biomarkers in bipolar disorder: a positional paper from the

20 International Society for Bipolar Disorders Biomarkers Task Force. Aust N Z J Psychiatry 2013; 47:

$21 \quad 321-332$.

22 3. Gottesman II, Gould TD. The endophenotype concept in psychiatry: etymology and strategic

23 intentions. Am J Psychiatry 2003; 160: 636-645.

24 4. Beauchaine TP. The Role of Biomarkers and Endophenotypes in Prevention and Treatment of

25 Psychopathological Disorders. Biomark Med 2009; 3: 1-3.

26 5. Glahn DC, Knowles EE, McKay DR, Sprooten E, Raventos H, Blangero J, Gottesman II, Almasy L.

27 Arguments for the sake of endophenotypes: Examining common misconceptions about the use

28 of endophenotypes in psychiatric genetics. Am J Med Genet B Neuropsychiatr Genet 2014; 165 :

$29 \quad 122-130$.

This article is protected by copyright. All rights reserved 
6. Versace A, Andreazza AC, Young LT, Fournier JC, Almeida JR, Stiffler RS, Lockovich JC, Aslam HA, Pollock MH, Park H, Nimgaonkar VL, Kupfer DJ, Phillips ML. Elevated serum measures of lipid peroxidation and abnormal prefrontal white matter in euthymic bipolar adults: toward peripheral biomarkers of bipolar disorder. Mol Psychiatry 2014; 19: 200-208.

7. Murray C. J. L., Lopez A.D. The Global Burden of Disease: A Comprehensive Assessment of Mortality and Disability from Disease, Injuries, and Risk Factors in 1990 and Projected to 2020. Cambridge, Mass: Harvard University Press, 1996.

8. Baldessarini RJ, Tondo L. Suicide risk and treatments for patients with bipolar disorder. JAMA 2003; 290: 1517-1519.

9. Baldessarini RJ, Pompili M, Tondo L. Suicide in bipolar disorder: Risks and management. CNS Spectr 2006; 11: 465-471.

12 10. Manji HK, Quiroz JA, Payne JL, Singh J, Lopes BP, Viegas JS, Zarate CA. The underlying 13 neurobiology of bipolar disorder. World Psychiatry 2003; 2: 136-146.

14 11. van Meer G, Voelker DR, Feigenson GW. Membrane lipids: where they are and how they behave. Nat Rev Mol Cell Biol 2008; 9: 112-124.

12. Brown HA, Murphy RC. Working towards an exegesis for lipids in biology. Nat Chem Biol 2009; 5: 602-606.

13. Horrobin DF, Bennett CN. Depression and bipolar disorder: relationships to impaired fatty acid and phospholipid metabolism and to diabetes, cardiovascular disease, immunological abnormalities, cancer, ageing and osteoporosis. Possible candidate genes. Prostaglandins Leukot

21 Essent Fatty Acids 1999; 60: 217-234. 14. Scola G, McNamara RK, Croarkin PE, Leffler JM, Cullen KR, Geske JR, Biernacka JM, Frye MA, 23 DelBello MP, Andreazza AC. Lipid peroxidation biomarkers in adolescents with or at high-risk for bipolar disorder. J Affect Disord 2016; 192: 176-183.

26 deficit in patients with bipolar mania. Eur Neuropsychopharmacol 2003; 13: 99-103.

27 16. Peet M, Murphy B, Shay J, Horrobin D. Depletion of omega-3 fatty acid levels in red blood 28 cell membranes of depressive patients. Biol Psychiatry 1998; 43: 315-319. 
1 17. Adams PB, Lawson S, Sanigorski A, Sinclair AJ. Arachidonic acid to eicosapentaenoic acid

2 ratio in blood correlates positively with clinical symptoms of depression. Lipids 1996; 31 Suppl:

3 S157-61.

4 18. Maes M, Smith R, Christophe A, Cosyns P, Desnyder R, Meltzer H. Fatty acid composition in

5 major depression: decreased omega 3 fractions in cholesteryl esters and increased C20: 4

6 omega 6/C20:5 omega 3 ratio in cholesteryl esters and phospholipids. J Affect Disord 1996; 38:

$7 \quad 35-46$.

8 19. Stoll AL, Severus WE, Freeman MP, Rueter S, Zboyan HA, Diamond E, Cress KK, Marangell LB.

9 Omega 3 fatty acids in bipolar disorder: a preliminary double-blind, placebo-controlled trial.

10 Arch Gen Psychiatry 1999; 56: 407-412.

11 20. Grosso G, Pajak A, Marventano S, Castellano S, Galvano F, Bucolo C, Drago F, Caraci F. Role of omega-3 fatty acids in the treatment of depressive disorders: a comprehensive meta-analysis of randomized clinical trials. PLoS One 2014; 9: e96905.

21. Frangou S, Lewis M, McCrone P. Efficacy of ethyl-eicosapentaenoic acid in bipolar depression: randomised double-blind placebo-controlled study. Br J Psychiatry 2006; 188: 46-50.

22. Schwarz E, Prabakaran S, Whitfield P, Major H, Leweke FM, Koethe D, McKenna P, Bahn S.

17 High throughput lipidomic profiling of schizophrenia and bipolar disorder brain tissue reveals

18 alterations of free fatty acids, phosphatidylcholines, and ceramides. J Proteome Res 2008; 7: 4266-4277.

23. Cecil KM, DelBello MP, Morey R, Strakowski SM. Frontal lobe differences in bipolar disorder

21 as determined by proton MR spectroscopy. Bipolar Disord 2002; 4: 357-365.

22 24. McNamara RK, Jandacek R, Rider T, Tso P, Stanford KE, Hahn CG, Richtand NM. Deficits in

23 docosahexaenoic acid and associated elevations in the metabolism of arachidonic acid and

24 saturated fatty acids in the postmortem orbitofrontal cortex of patients with bipolar disorder.

25 Psychiatry Res 2008; 160: 285-299.

26 25. Soares JC, Mallinger AG, Dippold CS, Frank E, Kupfer DJ. Platelet membrane phospholipids in

27 euthymic bipolar disorder patients: are they affected by lithium treatment? Biol Psychiatry

28 1999; 45: 453-457.

This article is protected by copyright. All rights reserved 
1 26. Demirkan A, Isaacs A, Ugocsai P, Liebisch G, Struchalin M, Rudan I, Wilson JF, Pramstaller PP,

2 Gyllensten U, Campbell H, Schmitz G, Oostra BA, van Duijn CM. Plasma phosphatidylcholine and

3 sphingomyelin concentrations are associated with depression and anxiety symptoms in a Dutch

4 family-based lipidomics study. J Psychiatr Res 2013; 47: 357-362.

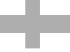

5 27. Di Paolo G, De Camilli P. Phosphoinositides in cell regulation and membrane dynamics.

$6 \quad$ Nature 2006; 443: 651-657.

7 28. Fountoulakis KN, Vieta E, Sanchez-Moreno J, Kaprinis SG, Goikolea JM, Kaprinis GS.

8 Treatment guidelines for bipolar disorder: a critical review. J Affect Disord 2005; 86: 1-10.

9 29. Lenox RH, Wang L. Molecular basis of lithium action: integration of lithium-responsive

10 signaling and gene expression networks. Mol Psychiatry 2003; 8: 135-144.

11 30. Jope RS, Song L, Li PP, Young LT, Kish SJ, Pacheco MA, Warsh JJ. The phosphoinositide signal

12 transduction system is impaired in bipolar affective disorder brain. J Neurochem 1996; 66: 2402-

132409.

14 31. Soares JC, Mallinger AG. Intracellular phosphatidylinositol pathway abnormalities in bipolar 15 disorder patients. Psychopharmacol Bull 1997; 33: 685-691.

16 32. Baum AE, Akula N, Cabanero M, Cardona I, Corona W, Klemens B, Schulze TG, Cichon S, 17 Rietschel M, Nothen MM, Georgi A, Schumacher J, Schwarz M, Abou Jamra R, Hofels S, Propping 18 P, Satagopan J, Detera-Wadleigh SD, Hardy J, McMahon FJ. A genome-wide association study 19 implicates diacylglycerol kinase eta (DGKH) and several other genes in the etiology of bipolar 20 disorder. Mol Psychiatry 2008; 13: 197-207.

21 33. Kato T, Shioiri T, Takahashi S, Inubushi T. Measurement of brain phosphoinositide

22 metabolism in bipolar patients using in vivo 31P-MRS. J Affect Disord 1991; 22: 185-190.

23 34. Silverstone PH, McGrath BM, Kim H. Bipolar disorder and myo-inositol: a review of the 24 magnetic resonance spectroscopy findings. Bipolar Disord 2005; 7: 1-10.

25 35. Atagun MI, Sikoglu EM, Can SS, Karakas-Ugurlu G, Ulusoy-Kaymak S, Caykoylu A, Algin O, 26 Phillips ML, Moore CM, Ongur D. Investigation of Heschl's gyrus and planum temporale in 27 patients with schizophrenia and bipolar disorder: a proton magnetic resonance spectroscopy 28 study. Schizophr Res 2015; 161: 202-209.

This article is protected by copyright. All rights reserved 
1 36. Manji HK, Lenox RH. Signaling: cellular insights into the pathophysiology of bipolar disorder.

2 Biol Psychiatry 2000; 48: 518-530.

3 37. Hahn CG, Friedman E. Abnormalities in protein kinase C signaling and the pathophysiology of

4 bipolar disorder. Bipolar Disord 1999; 1: 81-86.

5 38. McNamara RK, Ostrander M, Abplanalp W, Richtand NM, Benoit SC, Clegg DJ. Modulation of 6 phosphoinositide-protein kinase $\mathrm{C}$ signal transduction by omega-3 fatty acids: implications for

7 the pathophysiology and treatment of recurrent neuropsychiatric illness. Prostaglandins Leukot

8 Essent Fatty Acids 2006; 75: 237-257.

9 39. Harwood AJ. Lithium and bipolar mood disorder: the inositol-depletion hypothesis revisited.

10 Mol Psychiatry 2005; 10: 117-126.

11 40. Glahn DC, Williams JT, McKay DR, Knowles EE, Sprooten E, Mathias SR, Curran JE, Kent JW,Jr, 12 Carless MA, Goring HH, Dyer TD, Woolsey MD, Winkler AM, Olvera RL, Kochunov P, Fox PT,

13 Duggirala R, Almasy L, Blangero J. Discovering schizophrenia endophenotypes in randomly

14 ascertained pedigrees. Biol Psychiatry 2015; 77: 75-83.

15 41. Sheehan DV, Lecrubier Y, Sheehan KH, Amorim P, Janavs J, Weiller E, Hergueta T, Baker R, 16 Dunbar GC. The Mini-International Neuropsychiatric Interview (M.I.N.I.): the development and 17 validation of a structured diagnostic psychiatric interview for DSM-IV and ICD-10. J Clin Psychiatry 1998; 59 Suppl 20: 22-33;quiz 34-57.

42. Meikle PJ, Wong G, Barlow CK, Weir JM, Greeve MA, Maclntosh GL, Almasy L, Comuzzie AG, Mahaney MC, Kowalczyk A, Haviv I, Grantham N, Magliano DJ, Jowett JB, Zimmet P, Curran JE,

21 Blangero J, Shaw J. Plasma lipid profiling shows similar associations with prediabetes and type 2

22 diabetes. PLoS One 2013; 8: e74341.

43. Weir JM, Wong G, Barlow CK, Greeve MA, Kowalczyk A, Almasy L, Comuzzie AG, Mahaney

24 MC, Jowett JB, Shaw J, Curran JE, Blangero J, Meikle PJ. Plasma lipid profiling in a large population-based cohort. J Lipid Res 2013; 54: 2898-2908.

44. Meikle PJ, Wong G, Tsorotes D, Barlow CK, Weir JM, Christopher MJ, Maclntosh GL, Goudey

27 B, Stern L, Kowalczyk A, Haviv I, White AJ, Dart AM, Duffy SJ, Jennings GL, Kingwell BA. Plasma

28 lipidomic analysis of stable and unstable coronary artery disease. Arterioscler Thromb Vasc Biol 
1 45. Borg ML, Andrews ZB, Duh EJ, Zechner R, Meikle PJ, Watt MJ. Pigment epithelium-derived

2 factor regulates lipid metabolism via adipose triglyceride lipase. Diabetes 2011; 60: 1458-1466.

3 46. Boslem E, Maclntosh G, Preston AM, Bartley C, Busch AK, Fuller M, Laybutt DR, Meikle PJ,

4 Biden TJ. A lipidomic screen of palmitate-treated MIN6 beta-cells links sphingolipid metabolites

5 with endoplasmic reticulum (ER) stress and impaired protein trafficking. Biochem J 2011; 435:

$6 \quad 267-276$.

7 47. Almasy L, Blangero J. Multipoint quantitative-trait linkage analysis in general pedigrees. Am J

8 Hum Genet 1998; 62: 1198-1211.

9 48. Glahn DC, Curran JE, Winkler AM, Carless MA, Kent JW,Jr, Charlesworth JC, Johnson MP,

10 Goring HH, Cole SA, Dyer TD, Moses EK, Olvera RL, Kochunov P, Duggirala R, Fox PT, Almasy L,

11 Blangero J. High dimensional endophenotype ranking in the search for major depression risk

12 genes. Biol Psychiatry 2012; 71: 6-14.

13 49. Cheverud JM. A simple correction for multiple comparisons in interval mapping genome

14 scans. Heredity (Edinb) 2001; 87: 52-58.

15 50. Knowles EE, Carless MA, de Almeida MA, Curran JE, McKay DR, Sprooten E, Dyer TD, Goring

$16 \mathrm{HH}$, Olvera R, Fox P, Almasy L, Duggirala R, Kent JW,Jr, Blangero J, Glahn DC. Genome-wide

17 significant localization for working and spatial memory: Identifying genes for psychosis using

18 models of cognition. Am J Med Genet B Neuropsychiatr Genet 2014; 165: 84-95.

19 51. Mitchell BD, Almasy LA, Rainwater DL, Schneider JL, Blangero J, Stern MP, MacCluer JW.

20 Diabetes and hypertension in Mexican American families: relation to cardiovascular risk. Am J

21 Epidemiol 1999; 149: 1047-1056.

22 52. Falkenburger BH, Jensen JB, Dickson EJ, Suh BC, Hille B. Phosphoinositides: lipid regulators of 23 membrane proteins. J Physiol 2010; 588: 3179-3185.

24 53. Delage E, Puyaubert J, Zachowski A, Ruelland E. Signal transduction pathways involving

25 phosphatidylinositol 4-phosphate and phosphatidylinositol 4,5-bisphosphate: convergences and 26 divergences among eukaryotic kingdoms. Prog Lipid Res 2013; 52: 1-14.

27 54. Balla T. Phosphoinositides: tiny lipids with giant impact on cell regulation. Physiol Rev 2013;

28 93: 1019-1137.

This article is protected by copyright. All rights reserved 
1 55. Mitchell PB, Manji HK, Chen G, Jolkovsky L, Smith-Jackson E, Denicoff K, Schmidt M, Potter

2 WZ. High levels of Gs alpha in platelets of euthymic patients with bipolar affective disorder. Am J

3 Psychiatry 1997; 154: 218-223.

4 56. Wang HY, Markowitz P, Levinson D, Undie AS, Friedman E. Increased membrane-associated

5 protein kinase $\mathrm{C}$ activity and translocation in blood platelets from bipolar affective disorder

6 patients. J Psychiatr Res 1999; 33: 171-179.

7 57. Perez J, Tardito D, Mori S, Racagni G, Smeraldi E, Zanardi R. Abnormalities of cyclic adenosine

8 monophosphate signaling in platelets from untreated patients with bipolar disorder. Arch Gen

9 Psychiatry 1999; 56: 248-253.

10 58. Tardito D, Mori S, Racagni G, Smeraldi E, Zanardi R, Perez J. Protein kinase A activity in 11 platelets from patients with bipolar disorder. J Affect Disord 2003; 76: 249-253.

12 59. Ikenaga EH, Talib LL, Ferreira AS, Machado-Vieira R, Forlenza OV, Gattaz WF. Reduced

13 activities of phospholipases A2 in platelets of drug-naive bipolar disorder patients. Bipolar

14 Disord 2015; 17: 97-101.

15 60. Soares JC, Chen G, Dippold CS, Wells KF, Frank E, Kupfer DJ, Manji HK, Mallinger AG.

16 Concurrent measures of protein kinase $\mathrm{C}$ and phosphoinositides in lithium-treated bipolar

17 patients and healthy individuals: a preliminary study. Psychiatry Res 2000; 95: 109-118.

18 61. Soares JC, Mallinger AG. Abnormal phosphatidylinositol (PI)-signalling in bipolar disorder.

19 Biol Psychiatry 1996; 39: 461-464.

20 62. Friedman E, Hoau-Yan-Wang, Levinson D, Connell TA, Singh H. Altered platelet protein

21 kinase C activity in bipolar affective disorder, manic episode. Biol Psychiatry 1993; 33: 520-525.

22 63. Brown AS, Mallinger AG, Renbaum LC. Elevated platelet membrane phosphatidylinositol-4,5-

23 bisphosphate in bipolar mania. Am J Psychiatry 1993; 150: 1252-1254.

24 64. Karege F, Schwald M, El Kouaissi R. Drug-induced decrease of protein kinase a activity

25 reveals alteration in BDNF expression of bipolar affective disorder. Neuropsychopharmacology

$262004 ; 29: 805-812$.

27 65. Hahn CG, Friedman E. Abnormalities in protein kinase C signaling and the pathophysiology of 28 bipolar disorder. Bipolar Disord 1999; 1: 81-86.

This article is protected by copyright. All rights reserved 
66. Soares JC, Mallinger AG. Intracellular phosphatidylinositol pathway abnormalities in bipolar

2 disorder patients. Psychopharmacol Bull 1997; 33: 685-691.

3 67. Pandey GN, Dwivedi Y, SridharaRao J, Ren X, Janicak PG, Sharma R. Protein kinase C and

4 phospholipase $\mathrm{C}$ activity and expression of their specific isozymes is decreased and expression of

5 MARCKS is increased in platelets of bipolar but not in unipolar patients.

6 Neuropsychopharmacology 2002; 26: 216-228.

7 68. Malhi GS, Tanious M, Das P, Coulston CM, Berk M. Potential mechanisms of action of lithium 8 in bipolar disorder. Current understanding. CNS Drugs 2013; 27: 135-153.

9 69. Farooqui AA, Horrocks LA, Farooqui T. Modulation of inflammation in brain: a matter of fat. J 10 Neurochem 2007; 101: 577-599.

11 70. Tanaka K, Farooqui AA, Siddiqi NJ, Alhomida AS, Ong WY. Effects of docosahexaenoic Acid on 12 neurotransmission. Biomol Ther (Seoul) 2012; 20: 152-157.

13 71. Heneka MT, Carson MJ, El Khoury J, Landreth GE, Brosseron F, Feinstein DL, Jacobs AH, 14 Wyss-Coray T, Vitorica J, Ransohoff RM, Herrup K, Frautschy SA, Finsen B, Brown GC, 15 Verkhratsky A, Yamanaka K, Koistinaho J, Latz E, Halle A, Petzold GC, Town T, Morgan D, 16 Shinohara ML, Perry VH, Holmes C, Bazan NG, Brooks DJ, Hunot S, Joseph B, Deigendesch N, 17 Garaschuk O, Boddeke E, Dinarello CA, Breitner JC, Cole GM, Golenbock DT, Kummer MP. 18 Neuroinflammation in Alzheimer's disease. Lancet Neurol 2015; 14: 388-405.

19 72. Kim JE, Lyoo IK, Renshaw PF. Neurochemical and Metabolic Imaging in Bipolar disorder. In:

20 Strakowski SMed. The Bipolar Brain: Integrating Neuroimaging and Genetics. : Oxford University 21 Press, 2012: 79-102.

22 73. Kato T, Shioiri T, Takahashi S, Inubushi T. Measurement of brain phosphoinositide 23 metabolism in bipolar patients using in vivo 31P-MRS. J Affect Disord 1991; 22: 185-190.

24 74. Kato T, Takahashi S, Shioiri T, Murashita J, Hamakawa H, Inubushi T. Reduction of brain 25 phosphocreatine in bipolar II disorder detected by phosphorus-31 magnetic resonance 26 spectroscopy.J Affect Disord 1994; 31: 125-133.

This article is protected by copyright. All rights reserved 
1 75. Kato T, Takahashi S, Shioiri T, Inubushi T. Alterations in brain phosphorous metabolism in

2 bipolar disorder detected by in vivo 31P and 7Li magnetic resonance spectroscopy. J Affect

3 Disord 1993; 27: 53-59.

4 76. Yildiz A, Sachs GS, Dorer DJ, Renshaw PF. 31P Nuclear magnetic resonance spectroscopy

5 findings in bipolar illness: a meta-analysis. Psychiatry Res 2001; 106: 181-191.

6 77. Igarashi M, Ma K, Gao F, Kim HW, Greenstein D, Rapoport SI, Rao JS. Brain lipid

7 concentrations in bipolar disorder. J Psychiatr Res 2010; 44: 177-182.

8 78. Hamazaki K, Choi KH, Kim HY. Phospholipid profile in the postmortem hippocampus of 9 patients with schizophrenia and bipolar disorder: no changes in docosahexaenoic acid species. J

10 Psychiatr Res 2010; 44: 688-693.

11 79. Hamazaki K, Maekawa M, Toyota T, Dean B, Hamazaki T, Yoshikawa T. Fatty acid

12 composition of the postmortem corpus callosum of patients with schizophrenia, bipolar

13 disorder, or major depressive disorder. Eur Psychiatry 2016; 39: 51-56.

14 80. McNamara RK, Rider T, Jandacek R, Tso P. Abnormal fatty acid pattern in the superior

15 temporal gyrus distinguishes bipolar disorder from major depression and schizophrenia and

16 resembles multiple sclerosis. Psychiatry Res 2014; 215: 560-567.

17 81. Willey JZ, Rodriguez CJ, Carlino RF, Moon YP, Paik MC, Boden-Albala B, Sacco RL, DiTullio MR, 18 Homma S, Elkind MS. Race-ethnic differences in the association between lipid profile 19 components and risk of myocardial infarction: The Northern Manhattan Study. Am Heart J 2011;

$20 \quad 161: 886-892$.

21 82. Weir JM, Wong G, Barlow CK, Greeve MA, Kowalczyk A, Almasy L, Comuzzie AG, Mahaney

$22 \mathrm{MC}$, Jowett JB, Shaw J, Curran JE, Blangero J, Meikle PJ. Plasma lipid profiling in a large 23 population-based cohort. J Lipid Res 2013; 54: 2898-2908.

24 83. Gimeno D, Kivimaki M, Brunner EJ, Elovainio M, De Vogli R, Steptoe A, Kumari M, Lowe GD, 25 Rumley A, Marmot MG, Ferrie JE. Associations of C-reactive protein and interleukin-6 with 26 cognitive symptoms of depression: 12-year follow-up of the Whitehall II study. Psychol Med 27 2009; 39: 413-423.

This article is protected by copyright. All rights reserved 
1 84. Pasco JA, Nicholson GC, Williams LJ, Jacka FN, Henry MJ, Kotowicz MA, Schneider HG,

2 Leonard BE, Berk M. Association of high-sensitivity C-reactive protein with de novo major

3 depression. Br J Psychiatry 2010; 197: 372-377.

4 85. Zunszain PA, Hepgul N, Pariante CM. Inflammation and depression. Curr Top Behav Neurosci $5 \quad 2013 ; 14: 135-151$.

6 86. Barnett JH, Smoller JW. The genetics of bipolar disorder. Neuroscience 2009; 164: 331-343.

7

8 Table 1. Clinical Characteristics of the Sample

9

\begin{tabular}{|c|c|c|c|}
\hline 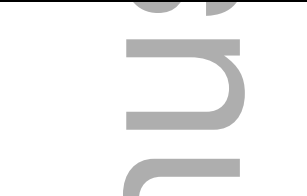 & $\begin{array}{l}\text { Number in } \\
\text { Affecteds } \\
(\mathrm{N}=9)\end{array}$ & $\begin{array}{l}\text { Number in } \\
\text { Relateds } \\
(\mathrm{N}=185)\end{array}$ & $\begin{array}{c}\text { Number in } \\
\text { Unrelateds } \\
(\mathrm{N}=373)\end{array}$ \\
\hline $\begin{array}{l}\text { Any depressive } \\
\text { disorder }^{\mathrm{a}}\end{array}$ & 9 & 54 & 137 \\
\hline $\begin{array}{l}\text { Any anxiety } \\
\text { disorder }\end{array}$ & 5 & 18 & 38 \\
\hline $\begin{array}{l}\text { Any alcohol use } \\
\text { disorder }^{\mathrm{a}}\end{array}$ & 6 & 77 & 113 \\
\hline $\begin{array}{l}\text { Any substance use } \\
\text { disorder }\end{array}$ & 1 & 32 & 32 \\
\hline $\begin{array}{l}\text { Diabetes } \\
\text { medication }^{\mathrm{b}}\end{array}$ & 0 & 5 & 26 \\
\hline $\begin{array}{l}\text { Lipid } \\
\text { medication }^{\mathrm{b}}\end{array}$ & 0 & 1 & 6 \\
\hline $\begin{array}{l}\text { Hypertension } \\
\text { medication }^{b}\end{array}$ & 0 & 8 & 27 \\
\hline $\begin{array}{l}\text { Diabetes } \\
\text { status }^{b}\end{array}$ & 0 & 9 & 45 \\
\hline $\begin{array}{l}\text { Heart } \\
\text { attack }^{\mathrm{b}}\end{array}$ & 0 & 1 & 2 \\
\hline
\end{tabular}

This article is protected by copyright. All rights reserved 


\begin{tabular}{|l|c|c|c|}
\hline $\begin{array}{l}\text { Heart } \\
\text { surgery }^{b}\end{array}$ & 0 & 1 & 0 \\
\hline Smoker $^{\mathrm{b}}$ & 2 & 58 & 77 \\
\hline
\end{tabular}

1 a collected at the time of GOBS assessment

$2{ }^{b}$ collected at the time of lipid data collection

3

4 Table 2. Means (and standard deviations) for age and percentage of females by degree of

5 relatedness to an individual with $\mathrm{BP}$.

6

\begin{tabular}{|c|c|c|c|}
\hline $\begin{array}{c}\text { Degree of } \\
\text { Relatedness }\end{array}$ & $\mathrm{N}$ & $\begin{array}{c}\text { Mean Age } \\
(\mathrm{SD})\end{array}$ & $\begin{array}{c}\% \\
\text { Female }\end{array}$ \\
\hline & 9 & $\begin{array}{c}34.65 \\
(4.05)\end{array}$ & 67 \\
\hline & 31 & $\begin{array}{c}45.84 \\
(13.12)\end{array}$ & 55 \\
\hline $2^{\text {nd }}$ & 21 & $\begin{array}{c}56.29 \\
(8.85)\end{array}$ & 76 \\
\hline $3^{\text {rd }}$ & 52 & $\begin{array}{c}46.09 \\
(12.16)\end{array}$ & 63 \\
\hline $4^{\text {th }}$ & 40 & $\begin{array}{c}45.26 \\
(11.83)\end{array}$ & 45 \\
\hline $5^{\text {th }}$ & 33 & $\begin{array}{c}36.50 \\
(7.16)\end{array}$ & 58 \\
\hline $6^{\text {th }}$ & 8 & 42.82 & 50 \\
\hline
\end{tabular}

7

8

9 Table 3. Heritability and degree of bipolar relatedness for all lipid classes.

This article is protected by copyright. All rights reserved 


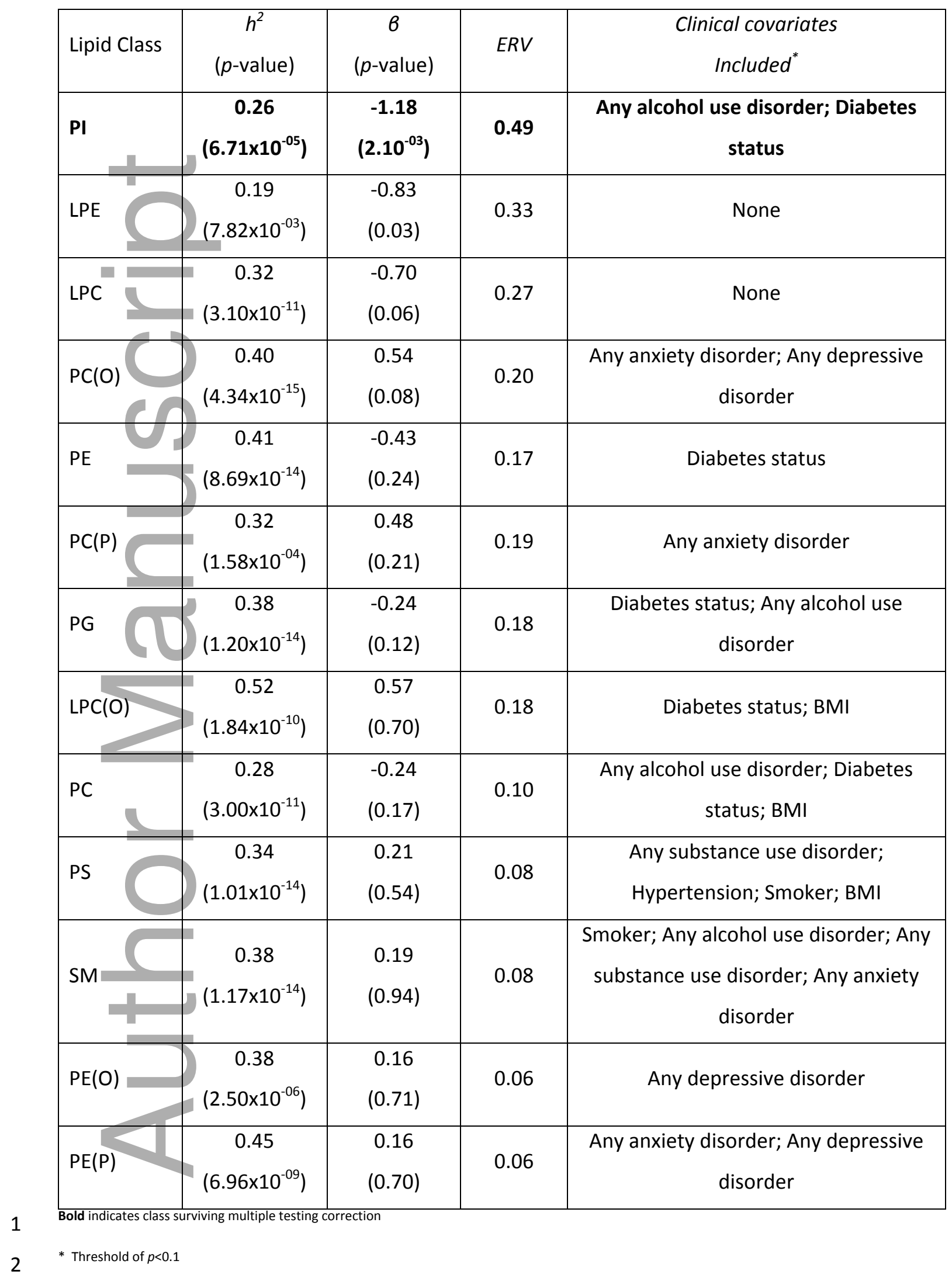

This article is protected by copyright. All rights reserved 
$\mathrm{PI}$ - phosphatidylcholine; LPE - lysophosphatidylethanolamine; LPC - lysophosphatidylcholine; PC(O) - alkylphosphatidylcholine; PE -

2

phosphatidylethanolamine; PC(P) - alkenylphosphatidylcholine; PG - phosphatidylglycerol; LPC(O) - lysoalkylphosphatidylcholine; PC -

3 phosphatidylcholine; PS - phosphatidylserine; SM - sphingomyelin; $\mathrm{PE}(\mathrm{O})$ - alkylphosphatidylethanolamine; $\mathrm{PE}(\mathrm{P})$ - alkenylphosphatidylethanolamine

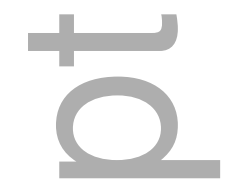

$\square$
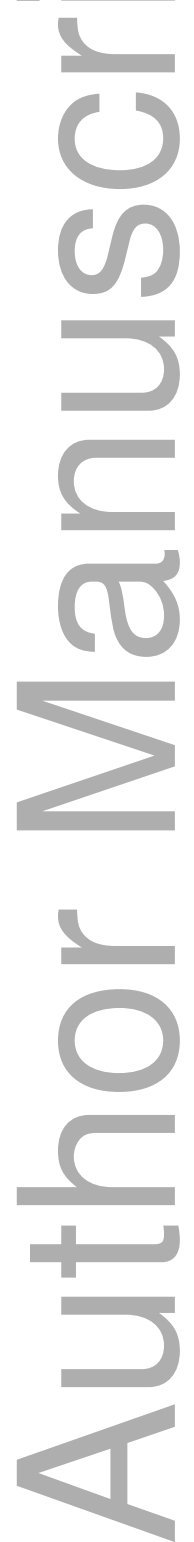

This article is protected by copyright. All rights reserved 

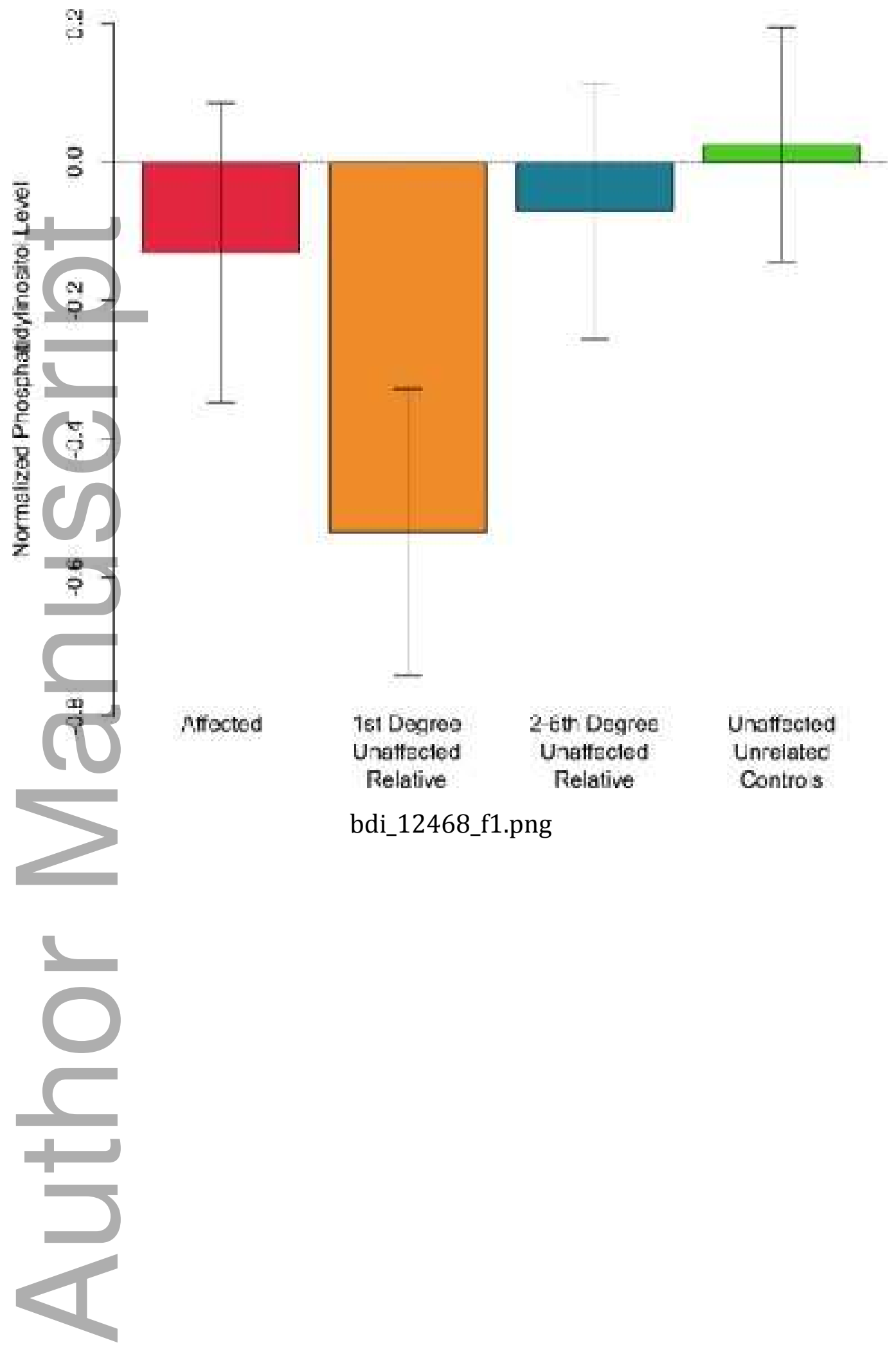

This article is protected by copyright. All rights reserved 


\section{University Library}

\section{- M I N E R VA}

\section{A gateway to Melbourne's research publications}

Minerva Access is the Institutional Repository of The University of Melbourne

\section{Author/s:}

Knowles, EEM;Meikle, PJ;Huynh, K;Goring, HHH;Olvera, RL;Mathias, SR;Duggirala, R;Almasy, L;Blangero, J;Curran, JE;Glahn, DC

Title:

Serum phosphatidylinositol as a biomarker for bipolar disorder liability

\section{Date:}

2017-03-01

\section{Citation:}

Knowles, E. E. M., Meikle, P. J., Huynh, K., Goring, H. H. H., Olvera, R. L., Mathias, S. R., Duggirala, R., Almasy, L., Blangero, J., Curran, J. E. \& Glahn, D. C. (2017). Serum phosphatidylinositol as a biomarker for bipolar disorder liability. BIPOLAR DISORDERS, 19 (2), pp.107-115. https://doi.org/10.1111/bdi.12468.

Persistent Link:

http://hdl.handle.net/11343/292484 